\title{
Construction and Demolition Waste Management in China through the 3R Principle
}

Published in: Resources, Conservation \& Recycling 129 (2018) 36-44, http://dx.doi.org/10.1016/j.resconrec.2017.09.029

Beijia Huang ${ }^{\mathrm{a}, \mathrm{b}^{* 1}}$, Xiangyu Wang $^{\mathrm{a}}$, Harnwei Kua ${ }^{\mathrm{c}}$,Yong Geng ${ }^{\mathrm{d}}$, Raimund Bleischwitz ${ }^{\mathrm{e}}$, Jingzheng Ren ${ }^{\mathrm{f}}$

\footnotetext{
${ }^{a}$ College of Environment and Architecture, University of Shanghai for Science and Technology, Shanghai, China ${ }^{\mathrm{b}}$ Department of Environment and Low Carbon Science, University of Shanghai for Science and Technology, China ${ }^{c}$ Department of Building, School of Design and Environment, National University of Singapore

${ }^{\mathrm{d}}$ School of Environmental Science and Engineering, Shanghai Jiao Tong University, Shanghai, China ${ }^{\mathrm{e}}$ Institute for Sustainable Resources, University of College London, London, United Kingdom

${ }^{\mathrm{f}}$ Department of Industrial and Systems Engineering, The Hong Kong Polytechnic University, Hong Kong, China
}

Abstract: Construction and demolition waste (CDW) accounts for 30\% to $40 \%$ of the total amount of waste in China. CDW is usually randomly dumped or disposed in landfills and the average recycling rate of CDW in China is only about 5\%. Considering there is big challenge in adoption of circular economy in CDW industry in China while related research is still limited, we conduct the CDW management analysis through $3 \mathrm{R}$ principle. Existing policies and management situations were investigated and analyzed based on the reduction, reuse and recycle principles. Results reveal that primary barriers of reducing CDW in China include lack of building design standard for reducing CDW, low cost for CDW disposal and inappropriate urban planning. Barriers to reuse CDW include lack of guidance for effective CDW collection and sorting, lack of knowledge and standard for reused CDW, and an under-developed market for reused CDW. As for recycling of CDW, key challenges are identified as ineffective management system, immature recycling technology, under-developed market for recycled CDW products and immature recycling market operation. Proposals to improve the current situation based on $3 \mathrm{R}$ principle are also proposed, including designing effective circular economy model, reinforcing the source control of $\mathrm{CDW}$, adopting innovative technologies and market

\footnotetext{
*Corresponding author: Beijia Huang Mobile: 13564538220 Email address: ywhbjia@163.com
} 
models, and implementing targeted economic incentives.

Keywords: construction and demolition waste; China; management; circular economy

\section{Introduction}

It is generally agreed that construction and demolition waste (CDW) management practices should be guided by the " $3 \mathrm{R}$ " - reduce, reuse and recycle principle (Peng 1997). However, the effectiveness of embracing such practices in China, where CDW accounts for about $30 \%$ to $40 \%$ of the total municipal waste, is still very limited; the recycling and reuse rate of CDW is less than 5\%. Comparatively, the CDW recycling and reuse rate can reach $70 \%$ to $95 \%$ in some developed countries, including the United States, Denmark, South Korea, Singapore, Japan and Germany (Xiao, 2015). Although the problem of low recycling and reuse rate has been attracting much attention from researchers in China since the early 1990s, waste management in the construction sector has not improved substantially (Wang 2010; Jin 2017). At present, around $75 \%$ of Chinese cities are facing what is now known as "CDW surrounding"(Jiao and Sun, 2013). Considering that CDW has leads to considerable environmental burdens and threats, reasonable treatment of the CDW is urgently needed.

Glushge et al. (1946) first proposed the concept of CDW recycling, with a focus on recycling discarded concrete. The positive contribution of recycling CDW is distinct when it is compared with traditional treatment methods. Ortizet et al. (2010) and Marzouk (2014) compared three different scenarios (recycling, incineration and land filling) and found that in terms of global warming potential, the most environmentally friendly way of treating CDW is recycling, followed by incineration and the last is land filling. $\mathrm{Wu}$ and $\mathrm{Hu}$ (2016) analyzed the eco-efficiency of three scenarios of CDW treatment - landfilling, recycling using private or state-owned facilities - and suggested that government should put more emphasis on state-owned recycling centers because of its highest eco-efficiency. Some researchers explored the 
status and shortcomings in managing CDW treatment in China. Katherine et al. (2017) conducted a survey on the awareness of circular economy concept in China's construction industry, and his results indicated that while there is industry wide awareness of the concept, clients, designers and subcontractors are the least informed and this is a key challenge for greater adoption. Yuan (2010) claimed that the major obstacles of CDW management in China are lacking well-developed waste recycling market, insufficient regulatory support and the predominant trend whereby building designs do not pay sufficient attention to waste reduction. After evaluating the economic feasibility for the recycling of CDW in Chongqing, Zhao et al. (2010) discovered that operating CDW recycling centers may face investment risks because of the high cost involved. Another group of researchers attempted to give suggestions for enhancing CDW reuse and recycling. Duan (2016) suggested that more attention should be put on improving the management of concrete, masonry (bricks and concrete/stone blocks), mortar and ceramic wastes, because these four types of CDW account for about $90 \%$ of the CDW in China and have the largest potential for recycling. Wang and Cao (2016) indicated that the CDW recycling in Handan is limited at certain materials such as concrete brick. In order to improve the comprehensive reuse and recycling of CDW, network information technologies should be applied to monitor the CDW production and treatment processes.

In general, although there is awareness of the urgency to promote CDW reduce and recycling, the current situation of CDW treatment is not good in China. Results of researches revealed that there are shortcomings in related CDW policies and management methods. Our literature review founds that although there are some studies discussed about the CDW management status, a detail review of the CDW management policies in China at the national level is still absent. Furthermore, the existing barrier analyses mostly only focus on reuse and recycling of CDW from different perspectives. Considering that it is crucial to reduce CDW at source, and there is big challenge in adoption of circular economy in CDW industry (Katherine et al., 2017), we contribute to the literature by conducting analysis of the CDW management by using the $3 \mathrm{R}$ principle. We believe that a comprehensive review of 
the CDW management policies and the current status of CDW treatment status, combined with interviews with the relevant stakeholders in the CDW industry, can help us better understand the current barriers in treating CDW in a circular economic way. This study will attempts to answer the following three questions: (1) What are the existing CDW management policies and what is the current situation of CDW management in China? (2) What are the challenges of managing CDW in China using the 3R principle? (3) What corresponding solutions can be suggested for enhancing effectiveness of managing CDW in China?

\section{Research framework and method}

\subsection{Research framework}

In order to better understand the current situation of CDW treatment and management in China, existing CDW related policies and treatment modes were reviewed. Subsequently, the challenges of CDW management in China were analyzed by interviews with most relevant stakeholders guided by the " $3 \mathrm{R}$ " principle. Challenges were reviewed and discussed in aspects of reducing, reuse and recycling. The views of 40 stakeholders in the field of CDW management were sought. Interviews were carried out through face-to-face or remote discussions (via phone). Some proposal regarding policy strategies for improving CDW management practices in China were brought forth based on the findings. In summary, the overall research framework is presented in Fig.1. 


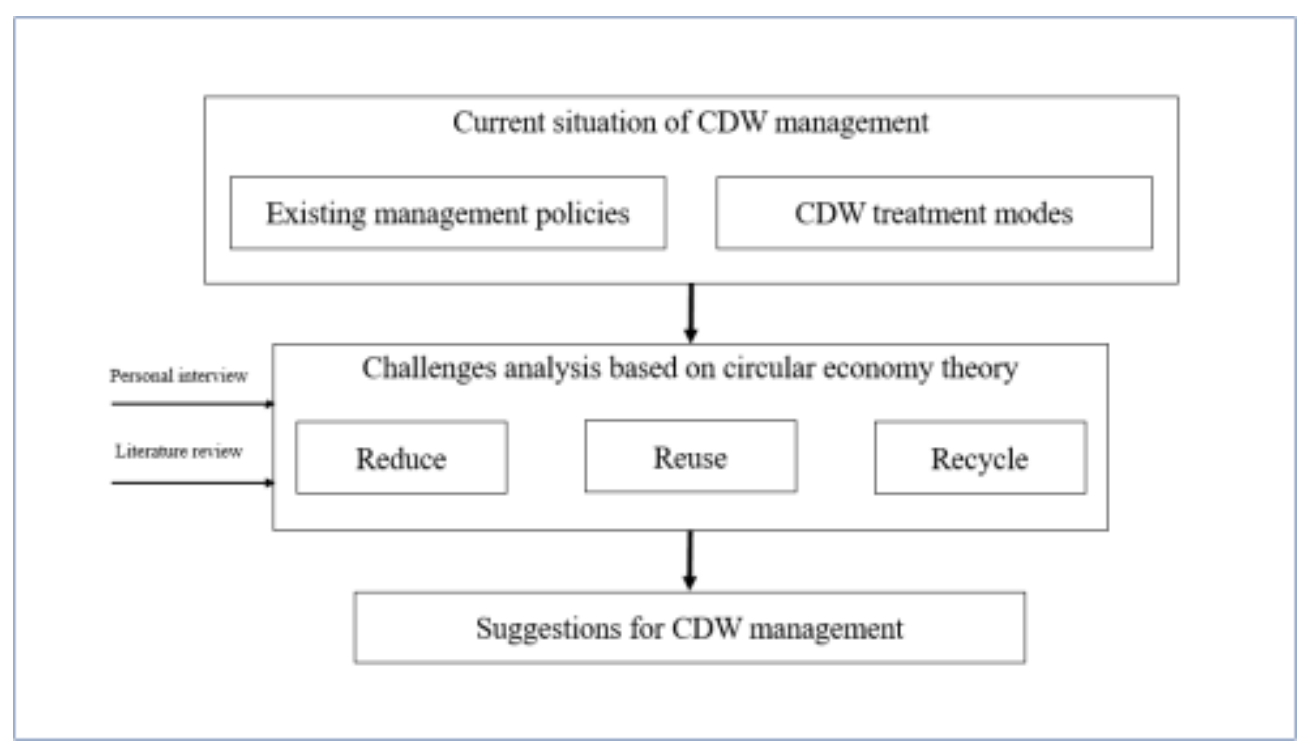

Fig.1. Research framework adopted for this study

\subsection{Research method}

In this paper, literature review and personal interviews were conducted to analyze the present barriers of CDW management in China. Articles related with the CDW treatment situation and barriers in China were reviewed to get the basic information. Interviews were conducted in order to get more information and thus have better understanding of the barriers. Three groups of stakeholders most relevant to the CDW industry were interviewed; they were (1) scholars/researchers (11 persons); (2) operators from building design (5persons), construction (5 persons) and demolition companies (9 persons); and (3) CDW treatment/ recycling companies (10 persons). These interviewees were selected based on the availability and their familiarity with the CDW industry. Subsequently, we conducted a semi-structured interview either face-to-face or over telephone. In order to have more comprehensive information, interviewed topics are not limited to those in questionnaires. All answers were collected and those that occurred at highest frequency were used to identify the CDW management barriers in China. The questions of the survey and corresponding answers are illustrated in the appendix. 


\section{Current state of CDW policies and treatment modes in}

\section{China}

This section provides a comprehensive review of the existing CDW management policies and the representative CDW treatment modes in China.

\subsection{Existing CDW management policies}

\subsubsection{National policies}

The first CDW management related policy document was issued in May 1995, and this is called the "city appearance and environmental sanitation management regulations". It defines the management actions for urban construction site materials and equipment. Following that, several related policies were issued by the Ministry of Housing and Urban-Rural Development and other governing bodies (refer to Table 1).

Table 1: Key construction and demolition waste management laws and regulations

\begin{tabular}{|c|c|c|c|}
\hline Year & Regulation name & Contents & Department \\
\hline 2003 & $\begin{array}{l}\text { Urban construction waste and } \\
\text { engineering sediment } \\
\text { management regulation } \\
\text { [City construction and } \\
\text { appearance letter No.5] }\end{array}$ & $\begin{array}{l}\text { Determine the City Appearance and } \\
\text { Environmental Sanitation Administrative } \\
\text { Department is in charge of the } \\
\text { management of CDW. }\end{array}$ & $\begin{array}{l}\text { Ministry of } \\
\text { Housing and } \\
\text { Urban Rural } \\
\text { Development }\end{array}$ \\
\hline 2005 & $\begin{array}{l}\text { Provisions on the } \\
\text { Administration of Urban } \\
\text { Construction Garbage } \\
\text { [Ministry of construction } \\
\text { No. 139] }\end{array}$ & $\begin{array}{l}\text { Specify that producers of construction } \\
\text { and demolition waste should bear the } \\
\text { responsibility to treat and dispose the } \\
\text { wastes. }\end{array}$ & $\begin{array}{l}\text { Ministry of } \\
\text { Housing and } \\
\text { Urban Rural } \\
\text { Development }\end{array}$ \\
\hline 2008 & $\begin{array}{l}\text { Financial subsidies for energy } \\
\text { saving building materials } \\
\text { [Financial building No.677] }\end{array}$ & $\begin{array}{l}\text { Provide financial subsidies (including } \\
\text { low interest loan) for CDW recycling. }\end{array}$ & $\begin{array}{l}\text { Ministry of } \\
\text { Finance }\end{array}$ \\
\hline 2009 & $\begin{array}{l}\text { Technical specifications for } \\
\text { construction waste disposal } \\
\text { [CJJ 134-2009] }\end{array}$ & $\begin{array}{l}\text { Provide guidance for construction waste } \\
\text { design and management of collection, } \\
\text { transportation, utilization and landfill }\end{array}$ & $\begin{array}{l}\text { Ministry of } \\
\text { Housing and } \\
\text { Urban Rural } \\
\text { Development }\end{array}$ \\
\hline 2011 & $\begin{array}{l}\text { Bulk solid waste } \\
\text { comprehensive utilization plan } \\
\text { [Resource Conservation and }\end{array}$ & $\begin{array}{l}\text { Develop demonstration projects for } \\
\text { resource utilization of construction and } \\
\text { demolition waste. }\end{array}$ & $\begin{array}{c}\text { National } \\
\text { Development } \\
\text { and Reform }\end{array}$ \\
\hline
\end{tabular}




\begin{tabular}{|c|c|c|c|}
\hline & $\begin{array}{c}\text { Environmental Protection } \\
\text { No.2919] }\end{array}$ & & Commission \\
\hline 2014 & $\begin{array}{c}\text { Implementation plan of } \\
\text { predominant resource } \\
\text { recycling project } \\
\text { [Resource Conservation and } \\
\text { Environmental Protection } \\
\text { No.3052] }\end{array}$ & $\begin{array}{l}\text { Suggest main building demolition } \\
\text { technologies, construction and demolition } \\
\text { waste classification technologies, } \\
\text { recycled aggregate treatment } \\
\text { technologies, etc. }\end{array}$ & $\begin{array}{c}\text { National } \\
\text { Development } \\
\text { and Reform } \\
\text { Commission }\end{array}$ \\
\hline
\end{tabular}

In addition to the abovementioned laws and regulations, there are also other policies supporting CDW management. For example, the National Development and Reform Commission also provide financial support for CDW recycling projects. Those demonstration projects in the eastern, central and western parts of China can obtain subsidies equal to $8 \%, 10 \%$, and $12 \%$ of their project investment respectively from the Commission (National Development and Reform Commission, 2015).

\subsubsection{Regional policies}

Since 2013, 14 provinces and 25 cities in China (China has 34 provincial administrative regions and 237 prefecture cities in total) have implemented a series of policies and regulations to manage CDW production, transportation and disposal (Zuo, 2015). The description of these local regulations is summarized in Table 2.

Table 2: CDW management regulations in Beijing, Shanghai Shenzhen and Qingdao

\begin{tabular}{|c|c|c|c|}
\hline Year & Regulation name & Contents & Department \\
\hline 2014 & $\begin{array}{l}\text { Notice on adjusting the fees for } \\
\text { non-resident garbage disposal in } \\
\text { Beijing } \\
\text { [Beijing development and } \\
\text { Reform Commission No.2662] }\end{array}$ & $\begin{array}{l}\text {--CDW transportation fee is set as } 6 \\
\text { RMB/ton within six kilometers, and } \\
\text { additional } 1 \mathrm{RMB} / \text { ton per kilometer will be } \\
\text { charged when exceeding six kilometers; } \\
\text {--CDW disposal fee is adjusted to } 30 \mathrm{RMB} / \\
\text { ton. }\end{array}$ & $\begin{array}{l}\text { Beijing Municipal } \\
\text { Commission of } \\
\text { Development and } \\
\text { Reform }\end{array}$ \\
\hline 2015 & $\begin{array}{l}\text { Construction waste and } \\
\text { engineering sediment disposal } \\
\text { regulations } \\
\text { [Government of Shanghai } \\
\text { Municipality No.50] }\end{array}$ & $\begin{array}{l}\text {--Require construction organizations to } \\
\text { include CDW disposal fees and } \\
\text { transportation costs in the construction } \\
\text { budget before applying construction waste } \\
\text { disposal permit. }\end{array}$ & $\begin{array}{l}\text { Shanghai Municipal } \\
\text { People's } \\
\text { Government }\end{array}$ \\
\hline 2016 & $\begin{array}{l}\text { Provisions on the Management of } \\
\text { Construction Waste in } \\
\text { Shanghai(draft) } \\
\text { Government of Shanghai }\end{array}$ & $\begin{array}{l}\text {--Strengthen the establishment of data } \\
\text { service platform, in order to better improve } \\
\text { service and management efficiency. }\end{array}$ & $\begin{array}{l}\text { Shanghai Municipal } \\
\text { People's } \\
\text { Government }\end{array}$ \\
\hline
\end{tabular}




\begin{tabular}{|c|c|c|c|}
\hline & \multicolumn{3}{|l|}{ Municipality No.50. } \\
\hline 2014 & $\begin{array}{l}\text { Transportation and disposal of } \\
\text { construction waste management } \\
\text { [Government of Shenzhen } \\
\text { Municipality No.260] }\end{array}$ & $\begin{array}{l}\text {--CDW organizations shall obtain a specific } \\
\text { transport permit; } \\
\text {--Construction waste disposal organizations } \\
\text { should establish a comprehensive } \\
\text { information platform for the management of } \\
\text { construction waste disposal. }\end{array}$ & $\begin{array}{l}\text { Shenzhen Municipa } \\
\text { People's } \\
\text { Government }\end{array}$ \\
\hline 2013 & $\begin{array}{l}\text { Municipal and rural construction } \\
\text { waste recycling management } \\
\text { regulations } \\
\text { [Qingdao Housing and Urban } \\
\text { Construction Department No.13] }\end{array}$ & $\begin{array}{l}\text {--CDW disposal fee can be fully returned by } \\
\text { the Ministry of Housing and Urban-Rural } \\
\text { Development if recycling rate of concrete, } \\
\text { brick, mortar and planting soil can reach } \\
30 \%, 20 \%, 10 \% \text { and } 10 \% \text { respectively. }\end{array}$ & $\begin{array}{l}\text { Qingdao Municipal } \\
\text { Committee of Urban } \\
\text { and Rural } \\
\text { Construction }\end{array}$ \\
\hline
\end{tabular}

A review and comparison of the previous policies found that regional policies usually give specific provisions under the guiding stipulations of national policies, especially in management responsibility, specific management measures and economic incentives. After reviewing these local policies, the most representative ones were found to be the CDW removal costs provision in Beijing, the special account and license requirement in Shanghai, the information platform in Shenzhen, and the economic incentive policies in Qingdao.

\subsection{Construction and demolition waste treatment in China}

With expanding urbanization and increasing reconstruction of old towns and new countryside in the recent ten years, the amount of CDW have been increasing rapidly. Although the existing regulations require CDW to be centrally deposited and treated, most of the CDW in China is disposed directly into landfill or dumped randomly (Gao, 2012). In addition, large quantities of CDW that are produced from infrastructure construction have been transferred from the urban to rural areas. As a result, more and more rural areas are now suffering from the so-called "CDW surrounding" issue. With the aim of understanding the current situation of CDW treatment in China, we attempt to describe the main management modes in the following sections.

\section{(1) CDW treatment in metropolitan areas}

Since the policies implemented in the two exemplary metropolitan cities - 
Beijing and Shanghai were found to be proactive, we examined the CDW treatment status in these two cities. As pointed out by $\mathrm{Wu}$ (2012), the average treatment rate of construction waste in most cities in China is between $3 \%$ and $10 \%$. In the case of Beijing, about 40 million tons of CDW was generated in 2014, of which $74 \%$ was disposed directly into landfills while less than 3\% was treated and recycled (Zuo 2011; Duan 2015). An investigation by the Beijing University of Civil Engineering and Architecture found that Beijing has 27 regular CDW disposal sites, but most disposals are done randomly in sites without qualification ( $\mathrm{Li}, 2008)$. In addition, there are only two construction waste recycling enterprises in Beijing - one located in Changping District and another one in Fengtai District till 2014 (China architecture design and construction, 2015). The framework of CDW management in Beijing was presented in Fig.3, which shows that the CDW in Beijing is divided into architecture sediment ${ }^{2}$, fragmented building material ${ }^{3}$, and unrecoverable construction waste ${ }^{4}$ that go to disposal without reusing or recycling. The thickness of the arrow indicates the amount of waste, thus we can easily find that most of the CDW is incinerated or buried directly, only some of the high added-value metals and other non -metals were recycled.

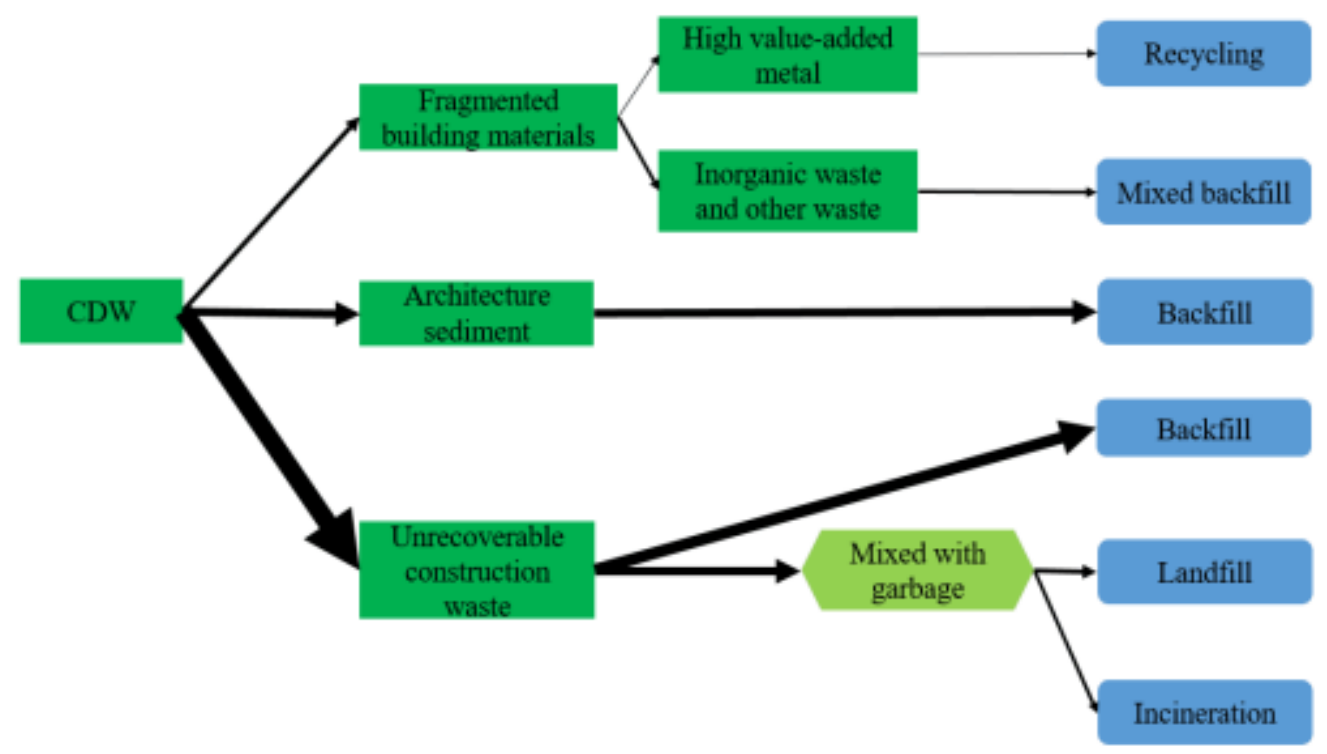

\footnotetext{
2 "Architecture sediment" is dreg/soil generated during building construction or demolition.

3 "Fragmented building materials" refer to those wastes which are produced during the construction and demolition process of the building and have high reuse and recycle value.

4 "Unrecoverable construction waste" consists of unwanted material produced directly or incidentally by the construction or demolition. Thses include building materials such as insulation, nails, electrical wiring, shingle as well as waste originating from site preparation such as dredging materials, tree stumps, and rubble.
} 
Fig.3. Flow of construction and demolition waste disposal in Beijing

(Thickness of arrows is for qualitative representations only)

As for Shanghai, the recycling rate of CDW is about $20 \%$, which is much higher than that in Beijing. According to statistic reports issued by National Bureau of Statistics of Shanghai Municipal Afforestation \& City Appearance and Environmental Sanitation Administration, 144 million tons of CDW were produced in Shanghai in 2014 (China Statistical Yearbook, 2015). The landfill rate of CDW in Shanghai is about $70 \%$ to $80 \%$. The rest of the combustible CDW (around $10 \%$ ) is burned directly or as fuel for some factory. As a coastal city, about $70 \%$ to $80 \%$ of the construction dregs are used for sea reclamation. This also happens in other coastal cities, including Shenzhen, Qingdao, Tianjin, Hong Kong and Macao. There are only two CDW recycling enterprises in Shanghai - one located in Fengxian District and another in Minhang District (Research Report on the Present Situation and Prospect of China's Construction Waste Disposal, 2015). As show in Figure 4, the CDW disposal method in Shanghai is more specific than that in Beijing. After onsite sorting, the CDW is handled in any of the three ways - directly recycled, recycled after processing, or landfilled according to their characteristics.

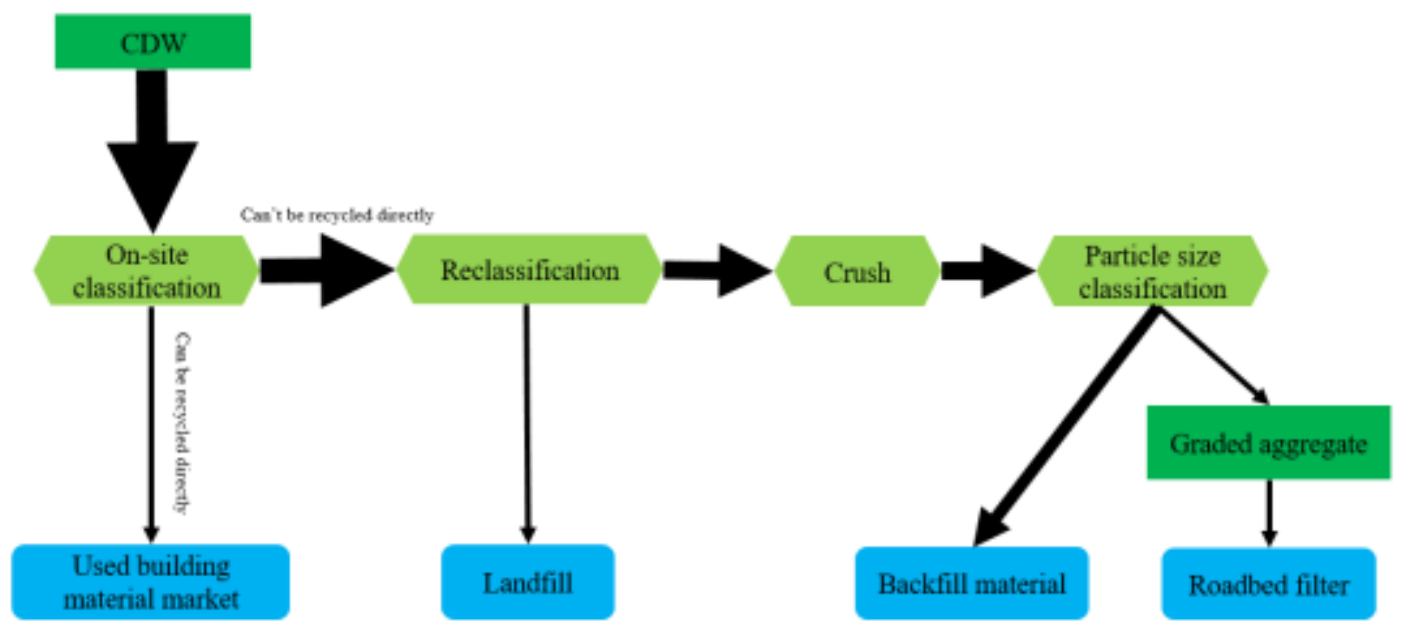

Fig.4. Flow of construction and demolition waste in Shanghai

(2) CDW management in rural areas

The rate of urbanization in China increased from $11.18 \%$ in 1950 to $56.1 \%$ in 2015 (National new urbanization Reports 2015). Accelerated reconstruction of the old towns and countryside in the recent ten years also contributed to rapid increase in the 
generation of CDW. In addition, large amounts of CDW produced by infrastructure construction are transferred from urban to rural areas. More and more rural areas are now suffering from the "CDW surrounding" issue that is due to illegally dumping of CDW. These dumping grounds are in the form of open-air piles, which release large amounts of harmful substances as a result of different physical, chemical and biological reactions (Zhu, 2005). CDW such as asbestos, cement and vinyl plastic tiles can even decrease the fertility of farmland, and decrease the crop production in that area (El-Fadel, 1997).

\section{Analysis of challenges based on 3R principle}

In this section, the major challenges faced by the management of CDW in China are analyzed from the combined perspective of reduce, reuse and recycle concepts that form the foundation of circular economy.

\subsection{Reduce}

Among the 3R strategies for CDW, waste reduction is the optimal management measure due to it having the lowest adverse impacts on the environment. It is therefore regarded as the first priority when developing CDW management plans. However, according to the literatures and feedback from our interviewees, the condition for CDW reduction is not well developed in China, mainly due to the following reasons:

\section{(1) Lack of design standards for reducing CDW}

Review of the existing CDW management policies in China revealed that most of existing regulations target at treating rather than reducing CDW. The interviewees from architecture design institute implied that there are few regulations requiring them to consider CDW reducing during the architectural design stage. Only in the Chinese Green Building Certification Standard ${ }^{5}$ (2014), the ground foundation,

\footnotetext{
5 The Chinese Green Building Certification Standard was first issued in 2006 in China, which defines the definition of green buildings and provides green building evaluation method. The new version(GB/T 50378-2014) was issued in 2014 by the Ministry of Housing and Urban-Rural Development.
} 
structural system and structural elements are required to be optimally designed in order to save building materials.

On the other hand, all the interviewees especially the researchers proposed that rigorous standard for building designing and construction is urgently needed to reduce CDW. Mohd (2017) claimed that it is crucial to combine the C\&D waste reduction idea in the planning stage for enhancing resource efficiency. In recent years, Building Information Modeling (BIM) is very popular in China, and it is acknowledged that it is beneficial to reduce CDW through simulation of building modules and the construction process (Liu, 2015). However, there is a lack of industry standards that guide the use of BIM in the market. According to the "Research Report on Development Trend and Competitive Strategy of China's Prefabricated Industry" (2016), precast construction accounts for only $2-3 \%$ of the market, but this share is expected to increase. Even though precast construction has the potential to reduce construction waste, there is a lack of industry standards for the quality of concrete prefabricated assembly and the use of BIM in the precast construction market.

The two interviewees from architecture design institute also indicated low level of awareness of building material reduction and inadequate training as key obstacles to reducing CDW. A comparative survey of CDW minimization design in China (Hao, 2010) revealed that although the invested architecture designers in China think reducing CDW is important, most of them have no idea of how to reduce CDW in the building design process. Meanwhile, there is no guiding manual to train them how to reduce CDM. This situation is also confirmed by our interviewees.

\section{(2) Low cost for CDW disposal}

In China, the landfill discharge fee of CDW is USD $0.46-0.76^{6}$ per ton, which is relatively low compared to USD 5.00-15.00 per ton in USA, USD 11.34-90.717 per ton in Germany, and USD $9.60^{8}$ per ton in Japan (International Statistical Yearbook, 2014). The low treatment fee of CDW makes it difficult to encourage construction

\footnotetext{
${ }^{6}$ accounting by exchange rate on June 21,2016

7 accounting by exchange rate on June 21,2016

8 accounting by exchange rate on June 21,2016
} 
organizations to reduce CDW generation. According to the feedback of the two managers from construction companies, the relatively low construction waste landfilling charge indirectly encourages firms to choose to discard CDW, rather than recycling or reusing it.

From another point of view, high construction waste disposal costs can cause more illegal dumping. Therefore, to effectively encourage CDW reduction, stricter supervision and punishment must be concurrently enforced.

\section{(3) Inappropriate urban planning}

Demolition of buildings produces large amounts of CDW, and the demolition rate is considerably high in China - reaching $40 \%$ of the total construction area per year since 2006 (Chen, 2012). There are many "short lived" buildings in China, and some of these demolished buildings have not even been occupied at all. The average life span of buildings is 35 years in China, while the average life spans of buildings are much longer in other countries (such as 132 years in the United Kingdom and 74 years in the USA) (Su, 2012). The reason for such a big difference is the short-sighted urban planning process. Due to the general lack of rational urban planning, municipal constructions are often built repeatedly, resulting in a large number of CDW (Jin 2008). In many large and medium-sized cities, their urban structure is basic and difficult to make large-scale adjustments. But the city's existing infrastructure can't meet the growing demands due to the irrational urban design in many cases. For example, frequent changes to urban functional areas and pipeline network led to large numbers of housing and road surface reconstruction. It is widely agreed that accelerated urbanization and large-scale transformations of old cities are two of the main reasons for the existence of such "short lived" buildings (Fu, 2015). The scholars/researchers interviewed also gave similar feedback regarding the existence of these "short lived buildings" and the large amounts of CDW produced as a result of these buildings. 


\subsection{Reuse}

Reusing of CDW is the action or practice of using applicable building materials again, whether for its original purpose (conventional reuse) or to fulfill a different function (creative reuse or repurposing). Based on literature review and stakeholder interview, the key barriers of reusing CDW are found to be as follows.

(1) Lack of guidance for effective CDW collection and sorting

The manager of the CDW management company whom we interviewed stated that most of the collected CDW are mixed and contaminated, because they are not properly separated or sorted at source. This eventually leads to a relative lower efficiency of reusing and recycling CDW. Unlike municipal wastes, CDW need special treatment methods to be properly separated or sorted. For example, reinforcing bars are usually covered with cement, and so without separating the cement from the bars, both are difficult to be reused ( $\mathrm{Li}, 2006)$. Feedback from CDW demolition companies indicated that usually only scrap steel, doors and windows, bricks are collected onsite, whereas most of the CDW generated are directly transported to designated CDW disposal sites. There are no proper guidelines on how to classify CDW, thus limited the reuse potential of these CDW.

There are also operators from the informal sectors who collect high-value CDW privately and often without permission. Without professional guidance, their collection can destroy some high-quality materials such as doors and windows, bricks, waste steel bar and metal block, thus reducing the reuse efficiency of CDW.

(2) Lack of knowledge and standards for reused CDW

Since there is a lack of standards imposed on reused CDW materials, consumers usually doubt the qualities of reused CDW. Even interviewees from building construction companies responded that they seldom applied reused CDW, because the quality of these materials could not be guaranteed. In addition, materials made from reused CDW are oftentimes not in adequate supply (Zhou, 2005). Therefore, it is 
usually difficult to get the recognition of the market for building materials made from reused CDW.

\section{(3) Under-developed market for reused CDW}

Promoting the acceptance and use of building materials made from reused CDW requires a strong market. Unfortunately, China has not established a normalized reused building materials market to facilitate widespread circulation of materials in the building industry (Yang, 2017). Researchers interviewed pointed out that developing a mature market for reused building materials is an important prerequisite to promote the reuse of CDW. For instance, markets for second hand building materials are dispersed in communities throughout the USA, which can effectively enhancing the circulation of reused building materials (Shi, 2009). An example is the Vermont-based company known as Skagit Building Salvage (2016), which provides services of recycling building materials, preserving architectural heritage and providing an affordable source of reusable CDW. The company even provides deconstruction services to ensure that precious and reusable materials salvaged from building renovation or demolition projects are carefully recovered.

\subsection{Recycle}

The CDW recycling requires the breaking down of used items to make new materials and objects. Based on literature information and stakeholder feedback, the key barriers of CDW recycling are discovered as follows.

(1) Ineffective management system

As indicated by the policies related to CDW management (see in Table 1 and Table 2), various departments and governing bodies help to implement CDW treatment. The Provisions on the Administration of Urban Construction Garbage issued by the Ministry of construction in 2005 defines that Municipal Afforestation \& City Appearance and Environmental Sanitation Administration are in charge of the CDW management at the city level. Usually, the Municipal Transportation 
commission is responsible for transporting CDW. Environmental monitoring of CDW disposal site is under supervision of Municipal Environmental Protection Bureau. The Urban Administrative Bureau carries out inspection and give punishment to illegal CDW disposal actions (see Fig.2).

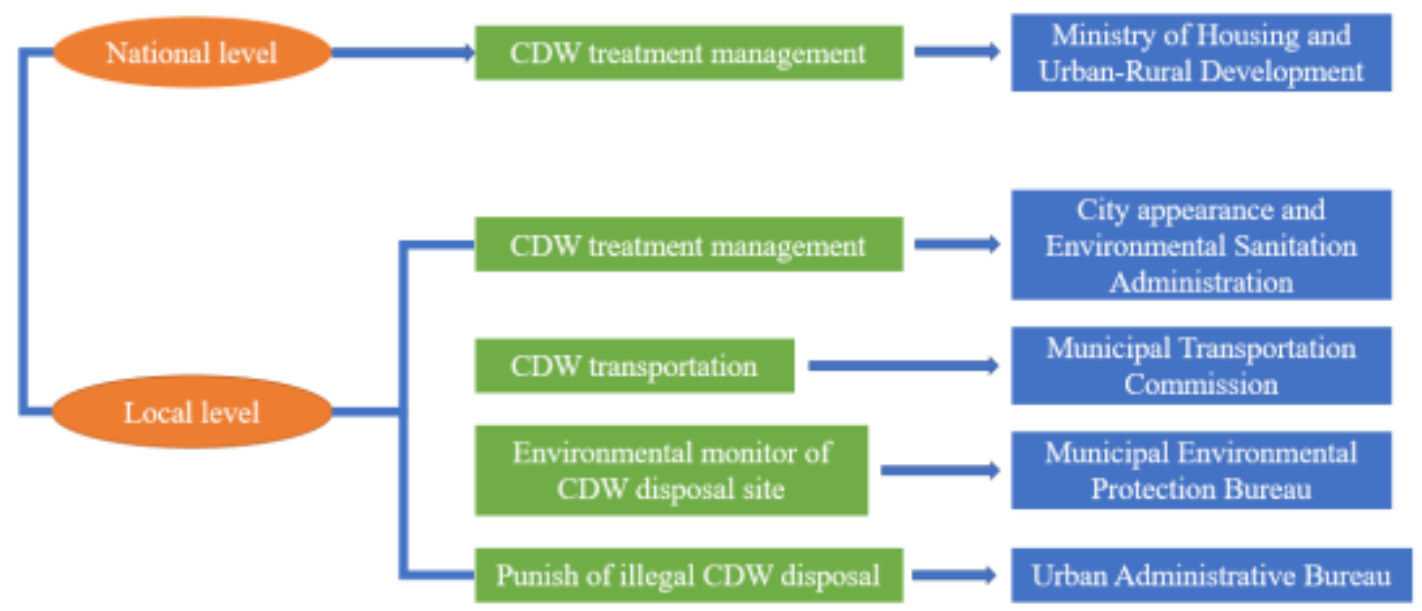

Fig.2. The different departments that are involved in the CDW management (general situation)

The communication and cooperation between these departments are however insufficient. Our interviewed scholars indicated that there is no known information sharing system between these departments on the quantities of CDW generated, collected, or treated. This partly leads to the current widespread improper disposal of large quantities of CDW.

(2) Immature recycling technology

CDW recycling in China is still in its infancy. CDW recycling in countries such as Japan, Germany and Singapore involved the application of mature CDW recycling technologies, including concrete and cement separation, concrete and aggregate recycling and even carbonization of CDW (China Architectural Design and Research Group, 2014). Specifically, the USA has the technological capability to produce recycled concrete that meets a wide variety of strength requirements (Liang, 2015). In contrast, only low and medium strength concrete can be produced for road surface and shock-absorbing cushion layer in China. Large amount of valuable wastes, such as light fixture, precious metals, plastic, glass and wooden products are recycled like 
normal waste, and so their full potentials to be recycled into value-added products have not been realized ( $\mathrm{Li}, 2009)$.

(3) Under-developed market for recycled CDW products

Efforts to popularize CDW recycling are challenged by many barriers in China. First of all, there are no quality standards for recycled products in China. Consumers thus may be hesitant to buy recycled CDW materials, since they cannot obtain enough information about the products concerned $(\mathrm{Hu}, 2011)$. In addition, feedback from our interviewee-directors from building construction companies-- also indicated that recycled building materials do not have price advantage over original materials due to the currently high cost of recycling treatment. Thus, the market for recycled CDW products has plenty of room for growth in China.

\section{(4) Immature recycling market operation}

At present, there are about $20 \mathrm{CDW}$ treatment enterprises and firms in China. However, without efficient CDW management and supervision system, it is difficult for these enterprises to obtain the raw materials needed to sustain normal and profitable business operations. Feedback from CDW treatment and recycling companies indicated that the unstable supply of CDW and high cost of treating and recycling CDW are the main challenges to their operations.

\section{Strategies for overcoming the barriers in CDW}

\section{management}

Through the analysis of the CDW disposal barriers, strategies for improving CDW management in China are proposed as following.

\subsection{Design effective circular economy model}

It is important to establish effective circular economy model for CDW, because recycled CDW can be utilized not only for the building industry, but also other industries. As shown in Fig.5, reducing and reusing of CDW should be carried out by 
stakeholders and professionals in building design and construction. For recycling and reusing CDW within the building industry, waste concrete, bricks, dregs and mortar can be converted into recycled materials, such as recycled concrete, lightweight block and recycled aggregate (Ying, 2013).

Recycled CDW can also be applied to other industries (refer to Fig. 6), because waste piles from construction sites do not only contains concrete, dregs, bricks, mortar and other solid waste, but also scrap metal, waste glass, waste wood, clay and shale slabs (Ying, 2013 ). Scrap metal can be recycled in metallurgical industry, after it is being smelted. Recycled metal scraps are commonly used for the manufacturing of automobile parts, electrical appliances, industrial containers, ductwork, and plumbing for new buildings. Waste glass can be used for glass industry after crushing and heating. Besides being used for making glass containers, recycled glass can replace materials such as alumina, hematite, nickel slag or silica sand as abrasive media for preparation of surfaces of manufacturing equipment parts, tanks, bridges and commercial ships. More importantly, using glass instead of nickel and silica helps to avoid any adverse health effects that come from chronic exposure to nickel or silica dust (Li, 2008). Waste wood can be used to make into pulp and eventually paper after re-processed. Clay and shale bricks can be reused in the ceramic industry to make into ceramic bricks. Further, crushed bricks can also be used as filler in paints or rubber plastic composites after being organically modified (Chen, 2016). 


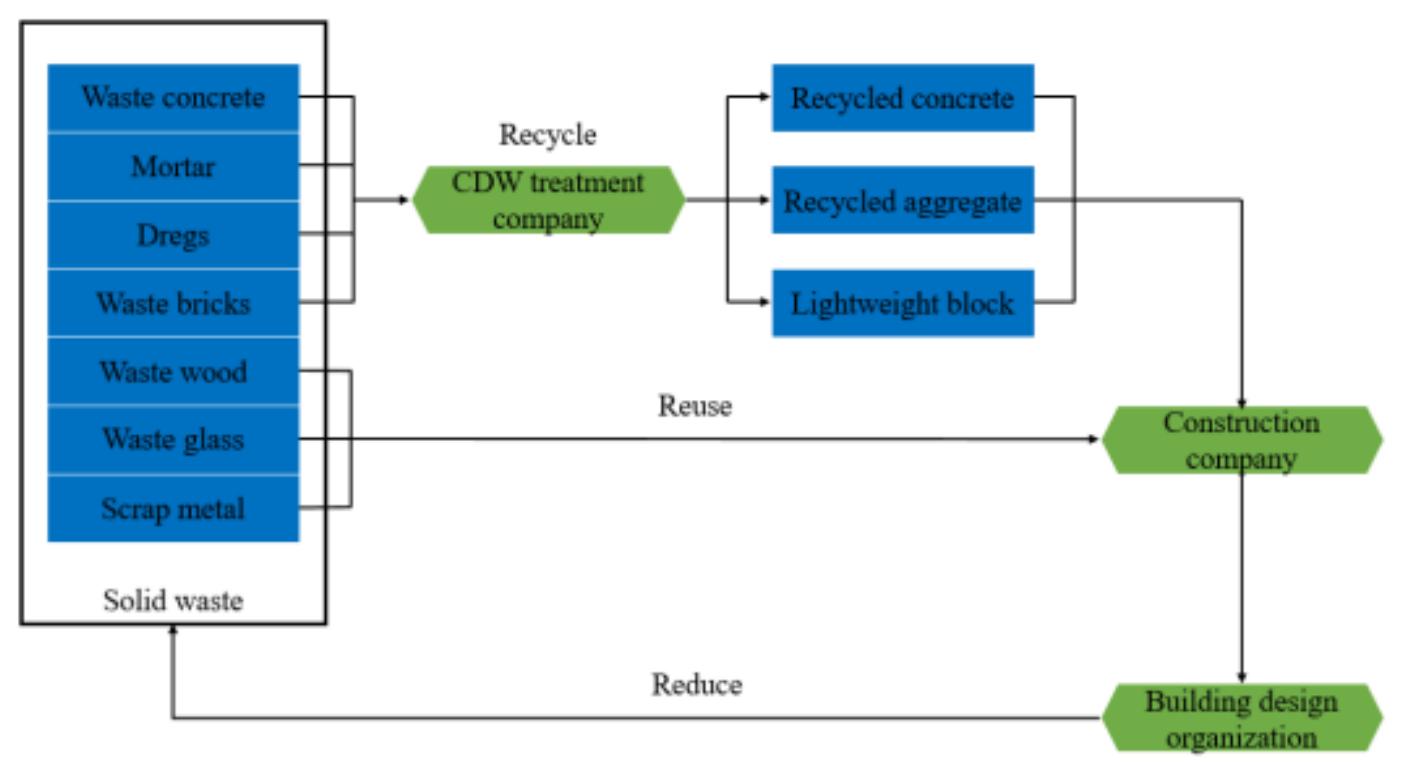

Fig.5. Circular economy mode for construction and demolition waste in the building industry

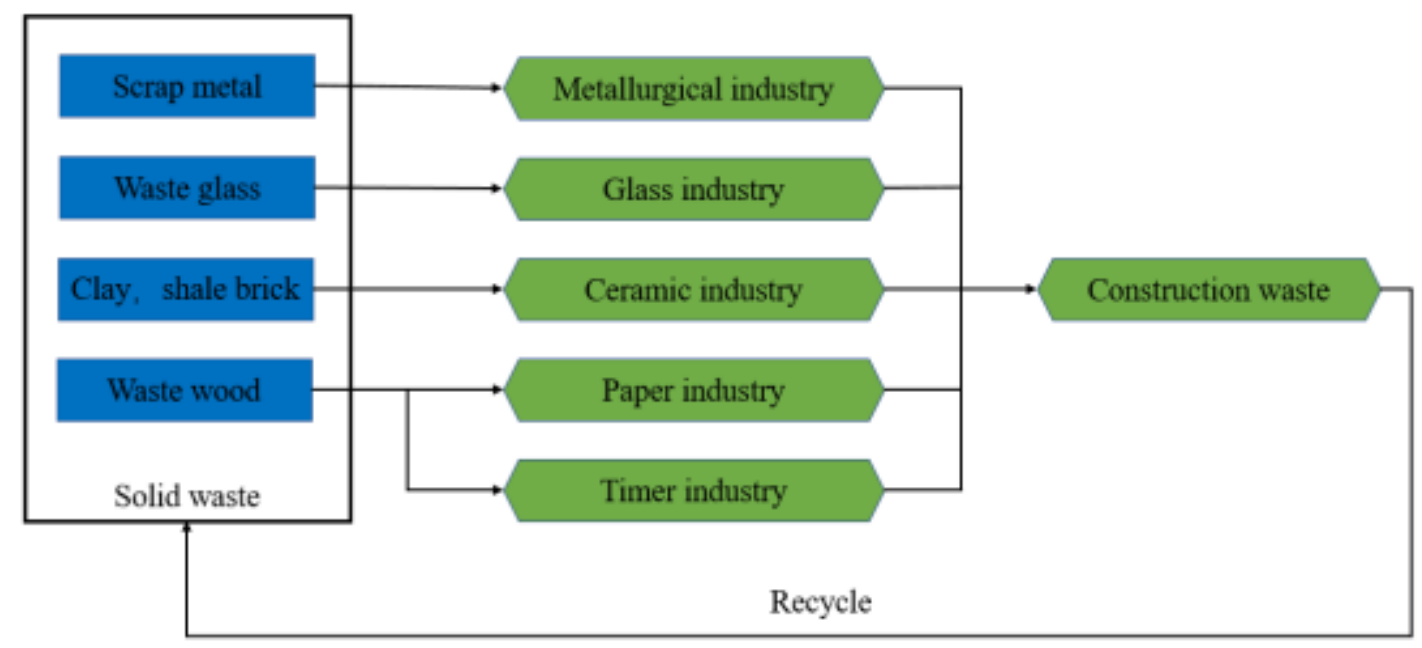

Fig.6. Circular economy mode for construction and demolition waste in other industries

\subsection{Reinforce the source control}

The interviewees in this study opined that control of the CDW source should be strengthened. Specifically, organizations involved in building designs and construction companies should sign an agreement to develop green construction program and jointly manage CDW.

In addition, in order to avoid the shortening of the life spans of buildings and civil infrastructures caused by rapid urbanization, adaptive reuse of buildings and 
infrastructure needs to be encouraged and sustainable urban planning should also be promoted. Achieving this requires increasing the awareness and collaboration of Ministry of Housing and Urban Rural Development, the Planning Bureau and Building Design Organizations. For example, an abandoned manufacturing plant can be modified into part of a creative industrial park, which is already becoming popular in China.

\subsection{Enhance supervision and management}

There is a serious lack of CDW supervision and management system in China. In order to enhance the management of CDW, several steps should be taken: (1) establish a "top down" regulatory system to standardize the management practices for CDW. Appoint a department (such as an environmental administration body) to lead the management of CDW. (2) Carry out process monitoring of CDW. The "slip system $^{9}$ " implemented in Japan can be adapted, for monitoring the treatment and delivery of CDW among producers, collectors, transporters and treatment companies. (3) Mete out strict punishment for illegal CDW treatment behaviors, such as illegal dumping.

In order to supervise the behavior of relevant stakeholders, the communication and cooperation between departments, such as City Administration Bureau and Sanitation Bureau should be strengthened. (4) Establish building design standards for reducing $\mathrm{CDW}$, and quality control standard for $\mathrm{CDW}$ recycling materials. (5) Encourage the application of CDW recycling materials by means of involving the purchasing of CDW recycling materials in government procurement system, or developing demonstration projects to popularize the advantages for materials recycled from CDW. Some of the models for implementing these demonstration projects were provided by Kua and Lee (2002). In addition, award points in green building evaluation systems can also be given to projects that utilize materials recycled from

\footnotetext{
9 They use 7 different vouchers/tickets in this system, namely A、B1、B2、C1、C2、D and E voucher/ticket. The emitters, collectors, transporters and treatment companies will be given different vouchers when the CDW comes to them and send the vouchers to next step. After the transport, processing and other links, the first emitter only in the A, B2, D, E votes are complete circumstances, can finally confirm the end of the construction waste.
} 
CDW.

\subsection{Adopt innovative technologies and market models}

As mentioned earlier, low quality collection and classification systems, and immature recycling technology are key barriers for reusing and recycling CDW. Thus, the research of technologies to reuse and recycle CDW should be strengthened. Technologies that classify and sort CDW, and facilitate quality control of recycled material should be especially promoted. Precast Construction Technologies should also be promoted, since it not only reduces pollution caused during the construction and demolition process, but also facilitates the recovery and reuse of building materials without the need for destructive dismantling processes.

In addition, to reduce the cost of CDW recycling, technologies that reduce environmental pollution and energy consumptions during the CDW recycling process is also in urgent need. Special research grants should be set up for the Research, Development and Demonstration (RD\&D) of the technologies and projects for the recycling and reuse of CDW in China. There should be more developed market model, such as the Public-Private-Partnership in the CDW market. Furthermore, an information platform is necessary to provide more information on $\mathrm{CDW}$, such as generation quantities, generation locations, the carrying capacity of CDW landfills, and qualified CDW transportation and treatment companies. Technologies such as Global Positioning System (GPS) could be installed on vehicles used for transportation of CDW to record transport routes and their final destinations, so that the random disposal of CDW could be avoided to some extent.

\subsection{Economic incentives}

As discussed previously, financial subsidies can be considered for CDW treatment companies for their expansion of production, and promotion of the use of energy-saving materials recycling methods. However, most of the existing economic incentive policies are for CDW treatment companies. Therefore, not many companies 
have the motivation to enter the CDW treatment business. In addition, economic support is still not sufficient for sustaining businesses in CDW treatment, because this line of business is facing aforementioned barriers, including an under-developed market for recycled CDW products. As a matter of fact, a large percentage of the CDW enterprises in China are running into financial deficit. Appropriate economic incentive methods are in urgent need to promote the CDW market. These incentives may include increasing the loan limit, shortening the application period for loan and lowering rent of land for CDW management businesses.

As mentioned earlier, the low CDW discharge fee is one of the major obstacles for reducing CDW generation. Therefore, the collection and disposal cost of CDW should be increased, so that the construction companies will be forced to reduce CDW and/or engage in CDW reuse and recycling as much as possible.

\section{Conclusions}

The annual output of CDW in China is more than 1.5 billion tons, which has led to severe environmental and social problems. The amount is continuously growing at a high rate, especially after 2009. This study gave a comprehensive review of the existing CDW management policies and the CDW treatment conditions in metropolitan and rural areas, especially the CDW management in Beijing and Shanghai.

Challenges in CDW management in China were analyzed based on key concepts in circular economy theory. The most significant challenges identified include a lack of building design standard for reducing CDW, low cost for CDW disposal and inappropriate urban planning. As for reuse of CDW, the key barriers are discovered as lack of guidance for effective CDW collection and sorting, lack of knowledge and standard for reused CDW, under-developed market for reused CDW. For CDW recycling, primary obstacles are ineffective management system, immature recycling technology, under-developed market for recycled CDW products and immature recycling market operation. . These barriers have seriously obstructed the circular utilization of CDW. 
Based on these findings, suggestions to promote CDW management in China based on 3R principle were proposed. First of all, effective circular economy models in building and other related industries should be designed. In order to enforce reduction of $\mathrm{CDW}$, it is necessary to reinforce the source control. For example, building design and construction stakeholders should sign an agreement to develop green construction program in which they jointly manage the CDW. Enhance supervision and management is in urgent necessary for implementing reuse and recycle of CDW. Approaches of this aspect include establishing a coherent "top-down" regulatory system, carrying out process monitoring of CDW and implementing strict punishment for illegal CDW treatment behaviors. Innovative technologies are also essential for promoting circular economy of CDW. Other than promoting technologies of classification and separating of CDW, contributions of joint technologies such as precast construction and BIM should also be explored. Last but not the least, government should encourage economic incentive measures such as shortening the application period for loan and lowering rent of land for CDW management businesses. New market mode such as the Public-Private-Partnership should also be encouraged for relieving the economic pressures for CDW treatment/recycling companies.

The number of interviewees in our study is 40. However, semi-structured interview was carried out. Thus, we believe that the feedback we received is reflective and representative of the situation in China. Readers or those interested in China in the academic domain may deepen their understandings in managing CDW through this study. Suggestions raised in this analysis provide a reference for policymakers to adopt effective measures to improving the performance of CDW management. With increasing attention being put on sustainability issues, there is a trend for the national and local governments to enforce new CDW policies and regulations. Thus, a broader observation of the effectiveness of CDW management approaches, and feedback from key stakeholders would be appropriate for future researches on this topic. 


\section{Acknowledgements}

The research work of this paper was supported by a grant from the National

Natural Science Foundation of China (No.71403170; 71461137008).

\section{References}

Bossink, A.G. and Brouwers, H.J.H., 1996. Construction waste: quantification and source evaluation, Journal of Construction Engineering and Management, 122, 55-60.

Begum, R.A., Siwar, C., Pereira, J.J. and Jaafar, A.H., 2007. Implementation of waste management and minimization in the construction industry in Malaysia. Resources, Conservation and Recycling. 51, 190-202.

Beijing Zhongyuan Zhisheng Market Research Co., Ltd. Research Report on Development Trend and Competitive Strategy of China's Prefabricated Industry. Beijing: Beijing Zhongyuan Zhisheng Market Research Co., Ltd., 2016.

Chen, G.H., 2012. Thoughts on "short lived architecture" in China. Journal of Shenzhen Polytechnic. 01,67-72.

China Architecture Design and Research Group, Policy Research on Construction Waste Recycling and Reutilization. City Building Energy Conservation and Wall Materials Innovation Office, 2015, 38-44.

Duan, H., Li, J., 2016. Construction and demolition waste management: China's lessons. Waste Manage. Res. 2016, 34(5), 397-398.

Gluzhge, P.J., 1946. The work of scientific research institute Gidrotekhnicheskoye Stroitel'stvo. 4, 27-28.

Gao, Q.S., Lei, Q.C., He, H., 2012. The Reason and Countermeasure of the Slow Development of Construction Waste Recycling Industry in China. Ecological Economy. 12, 128-135.

Hao, YY., Kang, J., Current situation and potentials of construction waste minimization by design, a comparative survey between china and UK, building science, 2010(6):4-9

Hu, J., Xiao, Z., 2011. Ecological utilization of leather tannery waste with circular economy model, Journal of Cleaner Production. 19, 221-228.

Jiao, Y.W. and Sun, S.R., 2013. The Problems of Chinese Garbage Siege and Development Strategies. Ecological Economy. 31, 103-106.

Jin, Y.F., Zhao, J., 2008. The influence of construction waste on the environment and the Countermeasures. Henan Science and Technology. 11,36-37.

Jin. R.Y., Li, B., 2017. An empirical study of perceptions towards construction and demolition waste recycling and reuse in China. Resources, Conservation \& Recycling. 126, 86-98.

Li, Y., Zheng, Y., Chen, J.L., 2008. Policy Study on Construction Waste Reclamation in Beijing. Building Science.10, 04-10.

Liang, B., 2015. Countermeasures for the recycling and utilization of construction waste in our country based on the comprehensive utilization of foreign construction waste. Shanghai Building Materials. 04, 12-16.

Li, X.Z., Li, N., 2009. Experience and reference of construction waste recycling in developed countries. Global Perspective. 06, 41-45.

Li, D.H., Duan, Z.Z., 2006. Disposal of the Construction Waste and Recycling Economy. 
Optimization of Capital Construction. 27, 34-38.

Li, Y., Zheng, Y., Chen, J.L., 2008. Policy Study on Construction Waste Reclamation in Beijing. Building Science. 24(10), 4-10.

Liu, Z., 2015. A BIM-aided construction waste minimization framework, Automation in Construction. 59, 1-23.

Linghe net market research institute, 2015. Research Report on the Present Situation and Prospect of China's Construction Waste Disposal. Linghe net market research institute, Beijing.

Mohamed, M., 2014. Environmental and economic impact assessment of construction and demolition waste disposal using system dynamics. Resources, Conservation and Recycling. 82, 41-49

Mutasem E F, 1997. Environmental Impacts of Solid Waste Landfilling, Journal of Environment management. 50,1-25.

Mohd R E, 2017. Strategies for minimizing construction and demolition wastes in Malaysia. Resources, Conservation \& Recycling. 120, 219-229.

National Development and Reform Commission, National new urbanization Reports. Beijing: National Development and Reform Commission, 2015, 12-16.

National Development and Reform Commission, http://hzs.ndrc.gov.cn/newzwxx/201503/t201503-668109.html. Accessed on 2017.3.11

National Bureau of Statistics of the People's Republic of China, 2015. China Statistical Yearbook. China Statistics Press, Beijing.

Ortiz, O. Pasqualino, J.C., Castells, F. 2010. Environmental performance of construction waste: Comparing three scenarios from a case study in Catalonia, Spain. Waste Management. 30, 646654.

Poon, C.S., Yu, A.T.W. and Jaillon, L. 2004. Reducing building waste at construction sites in Hong Kong. Construction Management and Economics. 22, 461-70.

Policy Research on Construction Waste Recycling and Re-utilization China Architectural Design \& Research Institute, 2014.

Peng, C.L., Domenic E. S., Charles, J.K., 1997. Strategies for successful construction and demolition waste recycling operations. Construction Management and Economics. 15, 49-58.

Su, Z.L., 2012. The protection of urban style and historic buildings in the process of urbanization in China. Journal of Shanghai Normal University( Philosophy \& Social Sciences Edition). 41, $18-24$.

Shi, W.Y., 2009. The Study of Building Deconstruction and the Reuse of Building Materials in Foreign Countries, Master thesis, Tianjin: Tianjin University, Architectural Design and Theory.

Urban construction waste management regulations, Ministry of Housing and Urban Rural Development of the People's Republic of china. 2005

Tam, V.W.Y., Tam, C.M., 2006. A review on the viable technology for construction waste recycling. Resources, Conservation and Recycling. 47, 209-221.

Wu, J., Shen, L., 2012. Study on Resources Treatment of City Construction Waste. Ecology and Environment. 04, 57-60.

Wang, J.Y., and Yuan, H.P., 2010. Factors affecting contractors risk attitudes: case study from China. International Journal of Project Management. 29, 209-219.

Wu, J.B., Hu, M.M., and Shi, S.Y. . Eco-efficiency of construction and demolition waste recycling in Chongqing, China. Sustainable Built Environment Regional Conference. 2016, 398-403. 
Wu, H.Y., Duan, H.B., and Zheng, L., 2016. Demolition waste generation and recycling potentials in a rapidly developing flagship megacity of South China: Prospective scenarios and implications. Construction and Building Materials. 113,1007-1016.

Xiao, X.W., Feng, D.K. and Tian, W., 2015. Present situation and suggestions on recycling and utilization of construction waste in China. Construction Technique. 44, 6-8.

Yang, Z.S., 2017. Research on Processing Strategies of Construction Waste Based on 3R Principle, Value Engineering. 06,126-129.

Ying, Y., Xu, H.Z., 2013. Study on the Countermeasures of Building Waste Resource Based on 3R Principle. Business. 15, 270.

Yuan, H.P., Shen, L.Y. and Wang., J.Y., 2010. Major obstacles to improving the performance of waste management in China's construction industry, Facilities. 29, 224 - 242.

Zuo, Y., 2015. Research of Chinese construction waste resource utilization and Recommendations. Beijing, Beijing University of Civil Engineering and Architecture

Zuo, H.K., Fu, S.L., 2011. Research on the Construction and Distribution of Construction Waste Generation and Disposal Facilities in Beijing City. Environmental Sanitation engineering. 19(2), 63-64.

Zheng, L.N, 2017. Characterizing the Generation and Flows of Construction and Demolition Waste in China, Construction and Building Materials. 136, 405-413.

Zhou, X.L., 2005. Recycling Economy and China 's Construction Waste Management, Construction Economy. 06,14-17.

Zhu,S., Liu, Z.B., 2005. Environmental question and countermeasure of rubbish landfill yard, Journal of Liaoning Technical University. 24, 250-523.

Zhao, W., 2005. Construction and demolition waste management in China: analysis of economic instruments for solving a growing problem, WIT Press. 109, 471-480.

Zhao, W, Leeftink, R.B., Rotter, V.S. 2010. Evaluation of the economic feasibility for the recycling of construction and demolition waste in China-The case of Chongqing. Resource, conservation and recycling.54,377-389

Katherine, T.A., 2017. Circular economy in construction: current awareness, challenges and enablers, Institution of Civil Engineer. 170, 15-24.

\section{Appendix}

Table 1The main questions and answers of CDW management interview

\section{Relevant Scholars/Researchers (11)}

Q1: Do you think the CDW management in China is effective? If no, what do you think are the most serious shortcomings?

A1: No. The monitoring of CDW transportation and treatment process is quite ineffective; The communication and cooperation between relative management departments are insufficient. 
Q2: Do you think the CDW management regulations are supportive?

A2: There are many emerging CDW management regulations at national and local level. However, there are still lack of standards/regulations for guiding material reduction in building design and construction. Meanwhile, there is lack of standards for reused\& recycled building materials.

Q3: In your opinion, what are the main reasons for china's huge CDW generation?

A3: High speed of urbanization and inappropriate urban design.

Building design (5), construction (5) and demolition companies(9)

Q1: (for building design companies): Is there any training or guidance leading you to consider reducing CDW during your building design work?

A1: No training or guidance.

Q2 (for building construction companies): Do you use recycled materials that produced by CDW in the new building? If no, why?

A2: Seldom. The price of the recycled building materials is not attractive. Meanwhile, the quality of them cannot be guaranteed as there is no standard for recycled building materials.

Q3 (for building demolition companies): Do you separate CDW on site after demolition?

A3: Usually only scrap steel, doors and windows, bricks are collected onsite, whereas most of the CDW generated are transported to designated CDW disposal sites.

\section{CDW treatment companies(10)}

Q1: Is the CDW that you collected been well classified?

A1: No. Most of them are mixed. We have to pay much effort and cost to classify them.

Q2: What is the biggest difficulty in your company's operation? Why?

A2: A big challenge is the stable supply of CDW. Only with strict government monitoring and mature CDW recycling market can the stable supply of CDW be insured.

Q3: Is the economic incentive from the government is supportive enough for your company?

A3: No. The cost for treating and recycling CDW is very high, such as material screening, and reprocessing. We are still under high pressure for making profit. 